\title{
O DIÁLOGO ENTRE AS CORTES
}

\section{The dialogue between the courts}

\author{
ALAN FELIPE PROVIN ${ }^{1}$ \\ Universidade do Vale do Itajaí \\ alanprovin@univali.br \\ YURY AUGUSTO DOS SANTOS QUEIROZ \\ Universidade do Vale do Itajaí \\ yury.queiroz@hotmail.com
}

Cómo citar/Citation

Provin, A. F. y Santos Queiroz, Y. A. dos (2017).

O diálogo entre as cortes.

Anuario Iberoamericano de Justicia Constitucional, 21, 11 1-127.

doi: https://doi.org/10.18042/cepc/aijc.21.05

\section{Resumo}

O presente artigo explora a aplicação das fontes jurisprudenciais, constitucionais e legislativas estrangeiras e internacionais no direito interno, partindo do estudo

1 Mestrando do curso de Ciência Jurídica no programa de Pós-Graduação da Universidade do Vale do Itajaí (UNIVALI). Bolsista do Fundo de Apoio à Manutenção e ao Desenvolvimento da Educação Superior - FUMDES. Pós-graduando lato sensu em Direito Empresarial e Advocacia Empresarial pela Universidade Anhanguera - Uniderp. Especialista lato sensu em Direito Civil e Direito Constitucional pela Universidade Anhanguera - Uniderp. Bacharel em Direito pela UNIVALI. Professor na Universidade do Oeste de Santa Catarina (UNOESC) e Tabelião de Notas e Protestos da Comarca de Modelo/SC.

2 Mestrando do Programa de Pós-Graduação Stricto Sensu em Ciência Jurídica da Universidade do Vale do Itajaí (UNIVALI). Pós-graduando lato sensu em Direito Empresarial e dos Negócios pela UNIVALI. Bacharel em Direito pela UNIVALI. Advogado militante nas áreas de Direito Civil, Direito Previdenciário e Direito Ambiental. 
do uso das fontes alienígenas no ordenamento pátrio, correlacionando a consecução e primazia dos direitos humanos no âmbito do diálogo internacional, de forma a fortalecer a ocorrência de decisões que sejam congruentes com o ideal humanitário, na busca pelo fortalecimento do diálogo entre as cortes das naçóes, em uma verdadeira troca de experiências para a busca da melhor resposta judicial, por meio da metodologia de lógica indutiva sob a pesquisa bibliográfica.

\title{
Palavras-chave
}

Diálogo entre as cortes; direito estrangeiro; direitos humanos.

\begin{abstract}
This article explores the application of jurisprudential sources, constitutional and foreign and international law in domestic law, starting from the study use of alien sources in parental planning by correlating the achievement and primacy of human rights in the international dialogue in order to strengthen the occurrence of decisions that are consistent with humanitarian ideal, in the pursuit of strengthening the dialogue between the courts of nations, with a real exchange of experiences in the search for better judicial response, through the inductive logic methodology in the literature.
\end{abstract}

\section{Keywords}

Dialogue between the courts; foreign law; human rights. 


\section{SUMÁRIO}

I. INTRODUÇÃO. II. O DIREITO DOS OUTROS COMO FONTE DO DIREITO INTERNO. III. OS DIREITOS HUMANOS E O DIÁLOGO INTERNACIONAL. IV. O DIÁLOGO ENTRE AS CORTES. V. CONSIDERAÇÕES FINAIS. REFERÊNCIAS.

\section{INTRODUÇÃO}

O entrelaçamento entre as nações sempre pareceu algo natural quando aliados objetivos políticos e econômicos comuns. Assim, diversas guerras foram travadas na busca de objetivos comuns entre algumas nações, conflitantes com outros objetivos comuns de outras nações. No âmbito judicial, contudo, essa naturalidade não é vista com tanta frequência. Dada a soberania dos povos em se autorregularem, as cortes carecem de migração de ideias e fundamentos para fazer do seu próprio direito um espaço mais justo para seus jurisdicionados.

O objetivo da presente pesquisa, dessa forma, é explorar a aplicação do direito internacional e/ou estrangeiro no âmbito interno de uma nação, de forma a tornar o próprio direito pátrio mais fortalecido, em um diálogo entre as cortes judiciais.

Primeiramente, há de se analisar a aplicação do direito estrangeiro no solo nacional, de forma a averiguar as variáveis que pairam sobre a resistência dos estados soberanos em buscar fora soluções que o ordenamento jurídico próprio não é capaz de solucionar, ou, quando o faz, de forma insatisfatória ou inerme.

A partir disso, adentra-se no estudo da aplicação das decisões estrangeiras, do direito dos outros no âmbito dos direitos humanos, lastreando alguns fragmentos constitucionais sobre, destacando a importância do maior número de fundamentos possíveis para conseguir pôr a pessoa humana (de maneira verdadeiramente humana) no coração das decisōes judiciais.

Partindo desse pressuposto, levantam-se os questionamentos a serem desfragmentados no decorrer da pesquisa: A fundamentação de decisões nacionais no direito estrangeiro ofende a soberania do Estado? O diálogo entre as cortes pode contribuir para fortalecer os alicerces da justiça? 
Por fim, enfrentando a problemática proposta, elucidar-se-á acerca do diálogo entre as cortes, pautando-se na ideia de troca de informações entre as nações constituintes de estados soberanos, pautados na efetivação dos direitos humanos.

A importância do tema pode ser constatada quando visualizado que, por vezes, o ordenamento jurídico brasileiro carece de bases sólidas para decidir determinados casos, uma vez que não existe (e nem é de se esperar que exista) solução pronta ou programada para todos os acontecimentos levados a cabo no Judiciário. Assim, buscar-se-á a solução dos problemas mencionados, com base no ordenamento jurídico e interpretação constitucional e internacional do tema, ampliando, dessa forma, as perspectivas sobre o diálogo entre as cortes.

Quanto à metodologia empregada no artigo científico, este se realizou pela base lógica Indutiva, e foram utilizadas as Técnicas do Referente, da Categoria, do Conceito Operacional e da Pesquisa Bibliográfica, incluindo doutrina e jurisprudência (Pasold, 2008: 86).

\section{O DIREITO DOS OUTROS COMO FONTE DO DIREITO INTERNO}

O processo de globalização não afetou tão somente a política e economia. $\mathrm{O}$ judiciário e a postura dos que o compõem também passam por esse fenômeno. Assim, surge a ideia de desemparedamento territorial do diálogo, de forma que haja a comunicação internacional entre juízes, uma vez que, apesar de possuírem suas competências territoriais delimitadas, por força da globalização, são levados a um processo de abertura a outros procedimentos, decisões e instâncias judiciais, por meio de um diálogo multidimensional (Diniz, 2014: 88).

O direito, neste ponto, apresenta-se como um dos elementos centrais para o desenvolvimento da sociedade moderna, uma vez que possui papel garantidor da segurança jurídica em uma política e economia em constante movimento. Torna-se responsável pela capacidade de expansão controlada de códigos e leis na medida em que o mercado demande, assumindo o compromisso de amparar o capitalismo e a legitimação e racionalização do poder (Ribeiro, 2014: 13-15).

O ordenamento jurídico pátrio é reflexo da capacidade de autogoverno decorrente da soberania nacional e popular, está presente na manifestação do poder constituinte originário que ocasionou na Constituição da República Federativa do Brasil de 1988 (Silva, 2014: 61).

É possível dizer que outra consequência do processo de globalização foi a aproximação de sistemas jurídicos nacionais, os quais, por suas peculiaridades 
culturais, distinguem o modelo de solução de conflitos entre as sociedades. A aproximação dos sistemas permite a criação de elos, de mecanismos de tradução de instituições jurídicas que podem vir a contribuir para um diálogo entre juízes (Marinho y Silva, 2014: 30).

A multiplicidade de fontes jurídicas sempre acompanhou o Direito, sendo certo que este não conta com apenas uma origem exclusiva. O emprego de textos normativos e decisões judiciais estrangeiras e internacionais sobre questôes jurídicas semelhantes retrata como o emprego do direito se dá por fontes além das normas internas (Rothenburg, 2014: 42). Isso tem como efeito prático a desarticulação do Poder Judiciário para inscrevê-lo em uma nova configuração do plano global (Araujo y Macedo, 2014: 4).

Certo é que, o juiz, ao exercer a jurisdição, não está vinculado tão somente às argumentaçōes jurídicas apresentadas pelas partes, podendo valerse, de ofício, de fontes jurídicas que considere adequadas para a solução dos pedidos formulados ou contestados. As normas de direito internacional, por exemplo, integram a norma jurídica de cada país, motivo pelo qual devem estar insertas nesse agir de ofício do magistrado (Rechsteiner, 2008: 241-242).

Nesse sentido, colhe-se jurisprudência do Superior Tribunal de Justiça Brasileiro, dos Autos do Recurso Especial de n.254544 MG, que já no início da década passada assinalava quanto ao dever do magistrado em colher de ofício a aplicação do direito estrangeiro. Segue:

Direito estrangeiro. Prova. Sendo caso de aplicação de direito estrangeiro, consoante as normas do direito internacional privado, caberá ao juiz fazê-lo, ainda de ofício. não se poderá, entretanto, carregar à parte o ônus de trazer a prova de seu teor $\mathrm{e}$ vigência, salvo quando por ela invocado. não sendo viável produzir-se essa prova, como não pode o litígio ficar sem solução, o juiz aplicará o direito nacional.

Antigamente, o uso de referências cruzadas entre cortes era eventual. Ainda hoje é possível visualizar que há resistência em algumas jurisdições sobre o uso de decisões estrangeiras, como se esta prática, de qualquer forma, diminuísse a soberania dos vereditos nacionais. Nos Estados Unidos, por exemplo, está implícita na discussão sobre o diálogo entre cortes a questão da legitimidade a valorização e interpretação de juízes de cortes estrangeiras sobre a aplicação dos direitos consagrados na Constituição Americana.

As práticas internacionais ao longo dos anos criaram a noção que hoje ainda é amplamente aceita de que o exercício do poder jurisdicional tem a produção dos seus efeitos restritas ao âmbito interno do Estado, lugar em que este exerce sua soberania (Araujo y Macedo, 2014: 4).

Silva afirma que, no Brasil, parte das causas disso começa nas próprias universidades de direito, em que há uma rígida separação de direito constitucional 
e direito internacional público e comunitário, havendo uma utilização muito pouco significativa de ideias constitucionais desenvolvidas em outros países além do Pacto de San José da Costa Rica (Silva in Bogdandy, 2010: 527-528).

A jurisdição sempre foi associada como um elemento de reconhecimento nacional. Contudo, a globalização e a produção judicial acarretou em uma jurisdição desnacionalizada, com diversos domínios jurídicos, afetando também a atividade dos tribunais nacionais (Araujo y Macedo, 2014: 3). Não se pode tolerar no ordenamento jurídico um preconceito com as normas provindas do direito estrangeiro, como se fossem alheias às do direito nacional (Rechsteiner, 2008: 247).

Conforme ensina Rothenburg (2014: 39-40), o «direito de fora» nunca esteve tão "dentro», uma vez que as experiências jurídicas externas, desde doutrina e jurisprudência à prática jurídica, devem ser e têm sido utilizadas pelos juízes e demais profissionais das áreas jurídicas. Ainda que a efetividade do direito estrangeiro seja posto em dúvida, não se pode negar sua evidência no mundo jurídico. $\mathrm{O}$ jurista contemporâneo não pode desempenhar seu papel estando alheio ao direito estrangeiro, dada a importância que assume na aplicação adequada do direito.

O Tribunal de Justiça do Estado de Minas Gerais na Apelação de n.409.921-8 já decidiu, inclusive, em jurisprudência datada de 2005, que «estabelecendo o título que a Lei de Nova York será aplicada no caso de execução do contrato, devem ser obedecidos os prazos prescricionais da lei estrangeira, o que não atenta contra a ordem pública do nosso país».

O exercício do poder jurisdicional desenvolve-se cada vez mais com base na interação entre ordens jurisdicionais distintas, sob parâmetros e diretrizes de decisões de cortes locais que devam estar atentas às decisões das cortes transacionais, buscando alcançar uma solução que atenda aos interesses e valores da comunidade internacional, conduzindo à multiplicação das fontes de onde se retiram os argumentos da decisão, com o reconhecimento da influência da jurisprudência estrangeira (Araujo y Macedo, 2014: 9).

Segundo Marinho e Oliveira (2014: 214), o uso de fontes externas pode servir para exemplo de parâmetros para solução de casos concretos, para demonstrar a necessidade de consenso internacional sobre o tema, ou, ainda, para justificar uma decisão semelhante ou contrária pelo juiz local.

A análise de fontes do direito externas e a análise da experiência jurídica alheia deve ter como objetivo a obtenção da melhor resposta aos problemas apresentados, respeitando as particularidades de cada sociedade, de forma que seja capaz oferecer dados relevantes para a construção de respostas adequadas, não conduzindo à mera apropriação e imitação da norma alienígena (Rothenburg, 2014: 43-44). 


\section{OS DIREITOS HUMANOS E O DIÁLOGO INTERNACIONAL}

O processo de expansão e universalização da proteção dos direitos humanos, reconhecidos como de interesse internacional, operou-se com vigor no Século Xx, principalmente diante do que o mundo presenciou na Segunda Guerra Mundial (Rothenburg, 2014: 43-44).

A pessoa humana foi posta no centro do constitucionalismo, sendo que o período pós-guerras fez com que o estado e as instituições internacionais deixassem de focar em análises meramente estruturais para aplicar o direito no sentido de que a pessoa humana é o centro das atençōes do novo mundo constitucional, devendo ela ser prestigiada, independentemente da origem das normas para a sua proteção (Conci in Mexxetti y Conci, 2015: 17).

Dessa forma, o exercício do poder jurisdicional entre sistemas jurídicos autônomos se torna cada vez mais interdependente, tornando as decisões judiciais locais em alicerces apoiados em argumentos transnacionais, ao discutir diferentes soluçôes possíveis para determinado caso concreto (Araujo y Macedo, 2014: 7).

Conforme Diniz (2014: 83), é necessário que haja um diálogo entre as cortes ou juízes, para que fosse possível propiciar a discussão sobre eventuais diferenças culturais e religiosas entre os diversos países, conduzindo à solução dos problemas juridicamente relevantes de cada nação mediante entrelaçamentos transconstitucionais entre ordens jurídicas diversas.

Isso pois, os direitos fundamentais tutelados pela Constituição, podem estar em conflito não só com normas materiais internas do direito privado, mas também com determinadas normas de direito estrangeiro, cabendo ao julgador decidir se aquela norma estrangeira fere a constitucionalidade do direito pátrio em que está sendo aplicada, ou se é possível haver a ponderação dos princípios e normas em jogo (Rechsteiner, 2008: 248-249).

A Constituição da África do Sul, por exemplo, estabelece em seu artigo 39, que quando da interpretação dos direitos fundamentais, as cortes, tribunais ou fóruns, deverão além de promover valores baseados numa sociedade democrática, que por sua vez é pautada na dignidade da pessoa humana, igualdade e liberdade, deverá considerar as leis internacionais e as estrangeiras ${ }^{3}$.

$\mathrm{Na}$ América do Sul, afirma Silva (2014: 522-523), é notável um déficit de diálogo entre as ideias constitucionais dos países locais, perdendo-se a oportunidade de fortalecer uma integração ainda insuficiente. Critica o

3 SOUTH AFRICA. Constitution of the Republic of South Africa, 16 dec. 1996. Disponível em: http://www.constitutionalcourt.org.za/site/constitution/english-web/index.html. Acesso em 12. jan. 2016. 
comodismo brasileiro em, por vezes, saber o que se está julgando nos Estados Unidos, sem nem conhecer o que se passa nos países vizinhos. Segundo Neves (2014), na América Latina há uma velha tradição de referências a dispositivos, jurisprudências e doutrinas constitucionais estrangeiras, principalmente norte-americanas e europeias.

A tradição legal da América Latina experimenta um momento peculiar em que a democracia e o constitucionalismo plantados no solo de nações muito jovens, assaz violentadas por diversos regimes ditatoriais, geram transformações e compromissos dirigidos por novos fundamentos da organização sociopolítica, em que a valorização dos direitos humanos, a ética republicana e accountability se mostram inegociáveis (Cunha y Guerra, 2014: 168).

Observar os problemas das demais sociedades pode ajudar a corte a ver um problema em uma perspectiva diferente, fornecendo um amplo leque de ideias e experiências, conduzindo a opiniões mais reflexivas, refletindo em uma comunidade transnacional consciente e contribuindo para uma jurisprudência global com decisóes nacionais de qualidade, com legitimidade e racionalidade (Araujo y Macedo, 2014: 24).

Alvarado explica que os alcances do diálogo podem ser apreciados quando o assunto é o mais marcado na história recente dos direitos humanos latino-americanos: os processos de transição da democracia de vários países que estavam imersos em ditaduras quebrando a ordem constitucional (Alvarado in Mazzetti y Conci, 2015: 261).

Principalmente quando são tratados os direitos humanos, verifica-se que o transconstitucionalismo envolve diversas ordens jurídicas, que se desenvolvem, igualmente, das mais diferentes formas na América Latina. O caminho mais adequado em matéria de direitos humanos parece ser o modelo de entrelaçamento entre ordens jurídicas, de tal maneira que todas se apresentem capazes de reconstruírem-se permanentemente mediante o aprendizado com as experiências de ordens jurídicas direta ou indiretamente interessadas na solução dos mesmos problemas jurídicos constitucionais envolvendo os direitos fundamentais ou humanos (Neves, 2014: 207).

Há, nos dias de hoje, uma intenção dos entes internacionais para a construção de mecanismos de proteção e promoção dos direitos humanos fundamentais. Diversas Cortes e Constituições nacionais já trazem os direitos fundamentais em seus valores e normas constitucionais (Silva, 2014: 60).

Não há como fugir da realidade que coloca a pessoa como centro e objetivo da proteção do direito, e não o estado. Assim, tanto interna quanto internacionalmente, a pessoa humana é e deve ser o fundamento de toda a ordenação jurídica dos direitos humanos (Conci, 2015: 127). 
Neste sentido, colhe-se recente jurisprudência do Supremo Tribunal Federal ${ }^{4}$, pelo meio do qual julgou um caso contra a literalidade do direito interno, com base nas normas de outros estados, no caso de aborto até o terceiro mês de gestação. Discorreu que:

Direito processual penal. Habeas corpus. Prisão preventiva. Ausência dos requisitos para sua decretação. Inconstitucionalidade da incidência do tipo penal do aborto no caso de interrupção voluntária da gestação no primeiro trimestre. Ordem concedida de ofício. A criminalização é incompatível com os seguintes direitos fundamentais: os direitos sexuais e reprodutivos da mulher, que não pode ser obrigada pelo Estado a manter uma gestação indesejada; a autonomia da mulher, que deve conservar o direito de fazer suas escolhas existenciais; a integridade física e psíquica da gestante, que é quem sofre, no seu corpo e no seu psiquismo, os efeitos da gravidez; e a igualdade da mulher, já que homens não engravidam e, portanto, a equiparação plena de gênero depende de se respeitar a vontade da mulher nessa matéria. Anote-se, por derradeiro, que praticamente nenhum país democrático e desenvolvido do mundo trata a interrupção da gestação durante o primeiro trimestre como crime, aí incluídos Estados Unidos, Alemanha, Reino Unido, Canadá, França, Itália, Espanha, Portugal, Holanda e Austrália (grifei).

Conforme Neves (2014: 196), há experiências em que os direitos humanos são postos à prova quando do conflito de normas locais e internacionais, como o caso da prisão perpétua prevista no Estatuto de Roma do Tribunal Penal internacional, ratificado pelo Brasil em 2002, e a própria Constituição Brasileira, que prevê de modo oposto, inclusive estando no rol de direitos fundamentais a proibição a tal prisão (que, conforme art. $60, \$ 4^{\circ}$, da CRFB/88, torna-se cláusula pétrea, não podendo ser abolida).

Lupi (2009: 298-300) afirma que as decisóes dos organismos internacionais não se incorporam necessariamente no ordenamento interno, nem são dotadas de tamanha autoridade que impeçam julgamentos contrários pelas cortes nacionais. $\mathrm{O}$ peso dos tratados na ordem hierárquica dos tipos normativos dos ordenamentos nacionais é definido com referência no próprio direito interno. $\mathrm{O}$ autor afirma que, ainda que o tratado prevaleça sobre a norma interna, isso somente ocorre por haver regra ou princípio do próprio Direito Interno autorizando essa primazia. Conforme Silva, há, em torno da integração jurídica, duas grandes indagações. A primeira sobre o nível hierárquico entre os tratados internacionais e supranacionais na ordem jurídica interna.

4 BRASIL, Supremo Tribunal Federal. Habeas Corpus no 124.306. Julgado em 29 nov. 2016. Disponível em: <www.stf.jus.br>. Acesso em 13 abr. 2017. 
A segunda, sobre a vinculação da jurisdição interna de cada estado-parte às decisões de tribunais internacionais ou supranacionais (Silva, 2014: 515).

Outro caso interessando diz respeito à colisão entre o art. $7^{\circ}, \mathrm{n}^{\circ} 7, \mathrm{da}$ Convenção Americana de Direitos Humanos, e o art. 5º, LXVIII, da Constituição Brasil, acerca do depositário infiel, permitido pela Carta Magna e proibido pela convenção. No julgamento do RE 466.343/SP, do RE 349.703/RS e do HC 87.585/TO, o Supremo Tribunal Federal entendeu que, as normas acerca de direitos humanos que não forem aprovados na forma do artigo $5^{\circ}$, $\$ 3^{\circ}$, da Constituição, não possuem caráter de emenda constitucional, mas, ainda assim, possuem hierarquia supralegal (Neves, 2014: 195).

Segundo o voto do Ministro Rezek, no caso acima, a Constituição não instituía a prisão do depositário infiel, apenas reconhecia a sua possibilidade, desde que regulamentada pelo legislador infraconstitucional. Aprovando o Pacto de São José da Costa Rica, o legislador nacional aceitou implicitamente afastar a prisão prevista na legislação nacional (Lupi, 2009: 305).

As Constituições latino-americanas, de um modo geral, estabelecem cláusulas constitucionais abertas, permitindo a integração entre a ordem constitucional e a ordem internacional, especialmente no campo dos direitos humanos, ampliando e expandindo o bloco de constitucionalidade (Piovesan, 2015: 86).

A Constituição colombiana, de 1991, por exemplo, estabelece, em seu artigo 91, que «los tratados y convênios internacionales ratificados por el Congreso, que reconocen los derechos humanos y que prohiben su limitación en los estados de excepción, prevalecen em el orden interno». E, na sequência, afirma que "los derechos y deberes consagrados en esta Carta, se interpretarán de conformidad con los tratados internacionales sobre derechos humanos ratificados por Colombia» (Colombia. Constituição, 1991).

Numa análise conjugada dos princípios norteadores das relações internacionais do Brasil, tal como esculpido no art. $4^{\circ}$ da Constituição da República Federativa do Brasil, denota-se que o constituinte já primou pela prevalência dos direitos humanos e pela cooperação entre os povos para o progresso da humanidade (incisos II e IX, respectivamente), devendo buscar, ainda, a integração econômica, política, social e cultural dos povos da América Latina (Brasil. Constituição, 1988).

Assim, os juízes nacionais podem se servir do direito internacional de direitos humanos como norma constitucional ou supralegal, a depender do que o ordenamento permite, podendo alegar que a instrumentalização da decisão se justifica em cumprimento a um compromisso internacional de garantia ou adaptação e interpretação que estão obrigados a seguir, em favor da pessoa humana (Alvarado, 2015: 258). 
Denota-se que a Corte Interamericana de Direitos Humanos, nesse sentido, tem declarado a incompatibilidade de normas nacionais que vão de encontro com a ordem interamericana, bem como aquelas que violam a Convenção Americana. Assim, essa interpretação acaba por constituir uma chave para o entrelaçamento dos sistemas jurídicos nacionais e internacionais, servindo como um dos elos fundamentais para a construção de uma rede constitucional de diferentes níveis (Gontijo, 2014: 237-238).

Ramos (2009: 817-818) afirma que a prática reiterada dos estados e das cortes internacionais é de considerar o direito interno um mero fato que expressa a vontade do Estado, uma vez que o Direito Internacional possuiria suas próprias fontes normativas. Para as Cortes, contudo, cabe analisar se os Estados cumpriram ou não seus compromissos internacionais, não aceitando escusas no sentido de superioridade da Constituição sobre os tratados.

Já o Tribunal Constitucional Alemão, aduz que as decisões da Corte Européia de Direitos Humanos não vinculam os tribunais alemães, mas que, apesar disso, desconsiderar as decisões daquela Corte não seria compatível com a proteção dos direitos humanos, sendo esta atitude tão equivocada quanto tentar aplicá-las diretamente (Silva, 2010: 521).

Assim, torna-se interessante se trabalhar a ideia de universalização dos direitos humanos na órbita interna dos países, de modo que todos possam falar a mesma língua, atendendo, ainda assim, às particularidades de cada nação.

\section{O DIÁLOGO ENTRE AS CORTES}

Cunha e Guerra (2014: 171) conceituam o diálogo entre juízes como um fenômeno "consistente na incorporação de argumentos extraídos de decisões no âmbito global, seja aquelas promanadas em tribunais estrangeiros ou em cortes de jurisdição eminentemente internacional (cortes regionais ou tribunais internacionais)».

Marinho e Silva (2014: 32) conceituam esse fenômeno informando que «o diálogo entre juízes reflete um alto grau de troca de precedentes judiciais entre cortes que não guardam necessariamente entre si vínculo formal de hierarquia. Entretanto, é possível a existência de um intercâmbio entre Cortes sem que haja necessariamente diálogo».

Com todas as transformações ocorridas no Estado Contemporâneo, sejam elas de cunho econômico, social ou cultural, a jurisdição acabou por enfrentar a exigência de um diálogo com as demais ordens jurídicas do sistema internacional, transpondo fronteiras, como se fosse um produto de exportação, passando de uma esfera nacional para outra e recursivamente volta para a 
esfera internacional para se infiltrar na ordem local (Araújo y Macedo, 2015: $3-4)$.

A questão se põe, assim, é na possibilidade de intercâmbio de normas equivalentes originárias de múltiplas fontes e o tratamento conferido a essas normas em casos semelhantes enfrentados ao redor do globo por tribunais dos mais diversos patamares (Cunha y Guerra, 2014: 173).

Marinho e Silva (2014: 29), neste ponto, lecionam:

A possibilidade de citação de decisões de cortes de outras jurisdições foi ampliada em razão do aumento da difusão destas decisões por meio da página da internet das cortes e do grau de confiabilidade dessas informaçôes. É possível ainda citar a existência de associações de juízes e do fomento a trocas de experiências em um mundo real ou virtual. Em se tratando de cortes internacionais, há ainda a disponibilização das decisōes em diferentes idiomas, o que também tem facilitado o acesso por juízes de primeira a última instância. Isso nos conduz a uma análise do papel da globalização e dos juízes no crescente processo de integração normativa, condições para a existência do diálogo entre juízes.

Com o auxílio da rede mundial de computadores (internet), é possível que se obtenha rapidamente informações úteis com relação ao teor, à vigência e à interpretação do direito estrangeiro, em especial quando o interessado domina a língua do ordenamento jurídico pesquisado, que, aliás, muitas vezes se encontra disponível em diversos idiomas (Rechsteiner, 2008: 252).

Para Araujo e Macedo (2014: 20), os meios juridicamente legítimos de coadjuvação entre cortes locais, estrangeiras, supranacionais e internacionais devem ser orientadas no sentido de promover a compreensão, discussão, reflexão e aproveitamento de novos e distintos argumentos ao debate judicial local.

A comunicação judicial, assim, ultrapassa as fronteiras nacionais, independentemente de coordenação intergovernamental. Os protagonistas do transjudicialismo não fazem parte unicamente do direito nacional, uma vez que complementam ou modificam as normativas locais com base em jurisprudências estrangeiras ou internacionais. Seus objetivos respondem à própria posição do Judiciário frente aos demais poderes do Estado para atender os fins «domésticos» (Araújo y Macedo, 2014: 20).

A Lei $n^{\circ} 13.105 / 15$, que promulgou o Novo Código de Processo Civil Brasileiro, por exemplo, prevê a possibilidade de cooperação jurídica internacional, que pode ter como objeto, além da colheita de provas e comunicação das partes envolvidas, a assistência jurídica internacional e a obtenção de prestação de informações sobre o ordenamento jurídico e sobre os processos administrativos ou jurisdicionais findos ou em curso de outro país. 
Interessante ressaltar, neste ponto, que, conforme Silva (2014: 68), a doutrina alemã vem desenvolvendo uma perspectiva chamada de heteroreferencialidade, na qual há a criação de um direito material não escrito sobre determinado fenômeno jurídico, com base em interpretaçōes, por sujeitos diferentes, sobre um conjunto de normas iguais. Pressupōe um ponto de observação alheio às suas estruturas próprias, para que as interpretações dadas por outras organizações igualmente constitucionais possibilitem a criação de um direito integrador.

Ainda de acordo com o autor, esse modelo de heteroreferencialidade ainda modifica o modo como os países integrantes da realidade constitucional não escrita interpretam e adaptam as mesmas obrigações supranacionais no âmbito interno de seus respectivos ordenamentos jurídicos. Araujo e Macedo (2014: 22) complementa informando que, «em síntese, o uso de decisões transnacionais permite que haja uma saudável fertilização cruzada de ideias, em que a análise das abordagens externas a temas semelhantes, enriquece a compreensão da corte acerca da questão».

Segundo Silva (2014: 517-520), sem instituições, legislações, parlamentos ou jurisdições comuns, não seria possível haver uma integração digna desse nome. Menciona que a América do Sul carece de uma integração jurídica como a da União Europeia. Assim, sugere o autor que seria possível, o diálogo constitucional é possível por meio de empréstimos e a migração de ideias. Empréstimos, envolvendo a importação de regras da constituição ou leis de um país para a constituição ou conjunto legal de outro, enquanto a migração de ideias estaria ligada ao livre câmbio de experiências, de ideias, de teorias.

Essa análise realizada por juízes, quando amparados por fontes estrangeiras, não desvalorizam a ordem jurídica interna, uma vez que aqueles possuem a obrigatoriedade de julgar os casos conforme a lei local. O diálogo pressupõe uma troca de informaçôes, seja ele de forma horizontal (sem hierarquia entre as cortes ou tribunais) ou vertical (em que há hierarquia, ou, mesmo não havendo, há o compromisso dos Estados em aplicar normas definidas em tratados) (Marinho e Oliveira, 2014: 214).

No âmbito nacional, os juízes passaram a analisar o cumprimento dos direitos e compromissos assegurados em tratados. O que pode mudar, de nação para nação, é a posição hierárquica que essas obrigações encontram em cada ordenamento jurídico.

A legitimação do diálogo afirma-se a partir do reconhecimento de que há argumentos vindos dos próprios tribunais, mas também de cortes alienígenas, e todos podem fazer partes das decisões, ainda que com argumentos contrários aos que decidido para além das fronteiras do estado nacional (Conci, 2015: 127). 
Rechsteiner (2014: 132) afirma que atribuir à jurisprudência a qualidade de fonte no direito internacional equivale afirmar que o juiz deve criar uma verdadeira norma jurídica perante as lacunas encontradas na legislação, inclusive pela via estrangeira.

Há de se entender que esse diálogo transnacional entre cortes constitucionais, contribui para uma justiça global e para um respeito recíproco na comunidade internacional, uma vez que o intercâmbio de decisões e entendimentos há por firmar uma uniformização na jurisprudência constitucional em seus diversos locais de aplicação (Araujo e Macedo, 2014: 26). É a partir do diálogo envolvente de saberes e atores diversos que se verifica a democratização da interpretação constitucional, de modo a resignificar o Direito (Piovesan, 2015: 87).

Conci (2015: 123) afirma que «esse diálogo de ordem constitucional exige que as cortes nacionais e internacionais se percebam como atores de um processo de integração em matéria de direitos humanos, trocando experiências, teorias e modos de interpretar dispositivos».

Esse entrelaçamento das normas internas e da repercussão internacional tem o intuito de possibilitar o mais amplo entendimento das controvérsias que se põem à mesa de julgamento, ainda que seja em favor de uma ou outra posição interpretativa para auxiliar nos casos desprovidos de fundamentos normativos ou de base jurisprudencial consolidada (Cunha y Guerra, 2014: 182).

Neves (2014: 194) leciona que esse «transconstitucionalismo» não se traduz tão somente ao «diálogo» entre as cortes, pois por vezes os direitos são conquistados em decorrência de relações altamente conflituosas entre as cortes de ordens jurídicas diversas. Assim, aponta-se para o fato de que surgem cada vez mais questôes que poderão envolver instâncias estatais, internacionais, supranacionais e transnacionais, assim como instituições jurídicas locais na busca da solução de problemas tipicamente constitucionais.

Essas tendências são um pouco mais visíveis em blocos econômicos envolvendo diversos países. Exemplifica-se que o Mercosul preocupa-se com a harmonização do direito processual civil internacional dentro do bloco, sendo indispensável que os protocolos com vigência no direito interno sejam efetivamente aplicados pelo Judiciário, devendo-se examinar a jurisprudência de todos os tribunais dos países integrantes do Mercosul (Rechsteiner, 2014: 364-365).

Essa nova concepção do processo judicial se vê refletiva em decisões tomadas por diversas cortes ao redor do globo, reproduzindo uma perspectiva de justificação da racionalidade argumentativa das cortes locais pelo paradigma decisional das cortes transnacionais nas ordens jurídicas domésticas. No caso sul-americano, obser- 
va-se que, em mais de uma oportunidade, cortes locais atuaram em claro diálogo com cortes transnacionais. No Brasil, por exemplo, o Supremo Tribunal Federal em 2009, na questão da exigência do diplomar de curso superior para o exercício da profissão de jornalista (Recurso Extraordinário no 511961), na mesma linha do entendimento exposto pela Corte Interamericana de Direitos Humanos na Opinião Consultiva $\mathrm{n}^{\circ} 5$, decidiu que tal obrigação consubstanciaria restrição injustificada à liberdade de imprensa. Da mesma forma, no julgamento do HC-87585 em 2008, o Supremo Tribunal Federal entendeu pelo status supralegal do Pacto de São José da Costa Rica, a Convenção Americana de Direitos Humanos, em território nacional, a demonstrar a deferência (Araújo e Macedo, 2014: 11).

Juízes e outros operadores devem conhecer e utilizar fontes de direito estrangeiro, como forma de manutenção, inclusive, dos direitos fundamentais, momento em que o diálogo de fontes apresenta-se como meio de aplicar a solução mais favorável ao efetivo cumprimento dos preceitos constitucionais internos (Rothenburg, 2014: 45-46).

Por derradeiro, há de se afirmar que, apesar de não haver uma vinculação ainda obrigatória no direito internacional e estrangeiro, a busca pelo amparo legislativo, doutrinário e jurisprudencial dos outros países visa à contribuição para a consecução dos fundamentos da república, dos seus princípios constitucionais e na própria afirmação dos direitos humanos esculpidos em tratados internacionais, aprovados pelo Brasil, seja nos moldes do art. $5^{\circ}, \$ 3^{\circ}$, seja da forma convencional.

\section{CONSIDERAÇÕES FINAIS}

Com a presente pesquisa, pôde-se averiguar a amplitude da discussão acerca do diálogo internacional como fonte autêntica do direito, de forma a fomentar um direito globalizado, acompanhando as transformações que a sociedade impõe ao Judiciário.

Deixou-se claro que a busca por normas estrangeiras não ofende a soberania nacional, e que, por muito tempo, isso restou estagnado nas ordens internas das nações em virtude dos grandes e trágicos acontecimentos bélicos que marcaram os últimos séculos.

No concernente aos direitos humanos, buscou-se demonstrar como o diálogo internacional pode contribuir para que a pessoa seja posta no foco das decisōes judiciais, no seu espaço mais humano, de forma que a migração de ideias e fundamentos estrangeiros levam ao conhecimento do que se passa em outras nações, podendo, assim, as cortes estabelecerem parâmetros para 
suas decisões, seja por aproximação na similitude dos casos enfrentados ou da repudia aos tratamentos tomados por outros Estados.

Com base nisso, foi demonstrado como ainda há resistência ou falta de conhecimento de algumas cortes na busca de respostas no espaço além de suas fronteiras, deixando consignado que até mesmo os tratados de direitos humanos passam por tratamentos desiguais a depender do ordenamento interno dos seus signatários.

Por fim, discorreu-se sobre o diálogo entre as cortes como forma de construir uma sociedade mais justa e democrática, buscando os fundamentos necessários para a solução dos problemas levados ao Judiciário nacional, construindo as respostas adequadas às demandas levantadas pelo povo que dia pós dia busca no Estado o cumprimento das necessidades básicas enquanto pessoa humana, sem se importar com a origem, nacional ou estrangeira, dos fundamentos essenciais para a estruturação da dissolução da dificuldade encontrada no caso concreto.

\section{Referências}

Alvarado, P. A. A. (2015). El diálogo judicial interamericano, un caminho de doble vía hacia la protección efectiva. In L. Mezzetti e L. G. A. Conci. Diálogo Entre as Cortes: a jurisprudência nacional e internacional como fator de aproximação de ordens jurídicas em um mundo cosmopolita. Brasília: OAB, Conselho Federal.

Araujo, L. C. M. de e Macedo, P. E. V. B. de. (2015). O Diálogo Institucional Entre Cortes Constitucionais: A Jurisdição Constitucional Justificada pelos Diálogos Transnacionais. In Encontro Nacional do Conpedi-UFS, XXIV, 2015, Aracaju/SE. Direito, Constituição e Cidadania: contribuiçôes para os objetivos de desenvolvimento do milênio. Disponível em: http://www.conpedi.org.br/publicacoes/c178h0tg.

Conci, L. G. A. (2015). Diálogo entre Cortes e o controle de convencionalidade: algumas reflexões sobre a relação entre o Supremo Tribunal Federal e a Corte Interamericana de Direitos Humanos. In L. Mezzetti e L. G. A. Conci. Diálogo entre as Cortes: a jurisprudência nacional e internacional como fator de aproximação de ordens jurídicas em um mundo cosmopolita (p. 117). Brasília: OAB, Conselho Federal.

Cunha, J. S. F. e Guerra, G. R. (2014). Expandir os horizontes das cortes é possível?: a abertura ao ativismo judicial transnacional e ao judicial borrowing a partir da disputa interpretativa sobre a lei de anistia travada entre o supremo tribunal federal e a corte interamericana de direitos humanos. Revista Fac. Dir. Sul de Minas, 30 (1), 167-184. Disponível em: http://www.fdsm.edu.br/site/posgraduacao/ volume2014.1/08.pdf.

Diniz, G. F. C. (2014). A Internacionalização Dos Direitos Face à Tensão Entre as Liberdades Individuais e as Diversidades Culturais e Religiosas: o diálogo de juizes como alternativa adequada? Brasília: UniCEUB. 
Duarte, C. S. (2014). A Contribuição do Direito Internacional dos Direitos Humanos Para o Reforço da Proteção Constitucional do Direito Social à Educação. Brasília: UniCEUB.

Gontijo, A. P. (2014). Diálogo Entre Juizes: bloco de constitucionalidade "ao avesso"? ou bloco de normatividade interamericano? Brasília: UniCEUB.

Lupi, A. L. P. B. (2009). O transjudicialismo e as cortes brasileiras: sinalizaçōes dogmáticas e preocupações zetéticas. Revista Eletrônica Direito e Política, 4 (3), 295-314. Disponível em: www.univali.br/direitoepolitica.

Marinho, M. E. e Oliveira, L. P. S. (2014). O Uso de Precedentes Judiciais de Jurisdições Estrangeiras em Matéria de Propriedade Intelectual. Brasília: UniCEUB.

Neves, M. (2014). Do Diálogo Entre as Cortes Supremas e a Corte Interamericana de Direitos Humanos ao Transconstitucionalismo na América Latina. Revista de Informação Legislativa, 51 (201), 193-214. Disponível em: http:/www2.senado.gov.br/ bdsf/item/id/502958.

Pasold, C. L. (2008). Metodologia da pesquisa jurídica: teoria e prática. Florianópolis: Milleniuum.

Piovesan, F. (2015). Direitos Humanos e Diálogos Entre Jurisdições. In L. Mezzetti e L. G. A. Conci. Diálogo Entre as Cortes: a jurisprudência nacional e internacional como fator de aproximação de ordens jurídicas em um mundo cosmopolita. Brasília: OAB, Conselho Federal.

Rechsteiner, B. W. (2008). Direito Internacional Privado: teoria e prática. São Paulo: Saraiva.

Ribeiro, H. (2014). Direito, Transição Paradigmática e Sociedade do Risco. Brasília: UniCEUB.

Rothenburg, W. C. (2014). Diálogo Internacional Entre Juizes: a influência do direito estrangeiro e do direito internacional na solução de casos de direitos fundamentais. Brasília: UniCEUB.

Silva, G. A. C. da. (2014). Diálogo Entre Juizes em Matéria Constitucional. Brasília: UniCEUB.

Silva, S. T. da. (2014). Diálogo Entre Juizes: condiçôes e critérios para a identificação do fenômeno "diálogo entre juizes». Brasília: UniCEUB. Disponível em: https://doi. org/10.13115/2236-1499.2014v2n11p212.

Silva, V. A. da. (2010). Integração e Diálogo Constitucional na América do Sul. In A. V. Bogdandy, F. Piovesan e M. Morales (orgs). Direitos humanos, democracia e integração jurídica na América do Sul (pp. 515-530). Rio de Janeiro: Lumen Juris.

South Africa. Constitution of the Republic of South Africa, 16 dec. 1996. Disponível em: http://www.constitutionalcourt.org.za/site/constitution/english-web/index.html. 